General Chemistry Peer-Led Team Learning (PLTL) Program at the University of Texas EI Paso (UTEP) for Fall 2020

$$
\text { Vanessa L. Rodriguez }
$$

University of Texas El Paso 


\begin{abstract}
The Peer-Led Team Learning (PLTL) Program at the University of Texas at El Paso (UTEP) is a program that provides students with the training necessary to host small workshops for students enrolled in their first two semesters of Chemistry. Peer Leaders are tasked with the responsibility of facilitating learning of Chemistry through the creation of practice problems, reviews and interactive games. As UTEP is a Latinx-serving university, a large portion of Peer Leaders and students are Latinx. Therefore, the PLTL program is empowering students through the development of Peer Leaders' leadership, and the strengthening of students' foundation in Chemistry, making them more likely to succeed in the STEM field. Peer Leaders in the program have witnessed the impact of the COVID-19 pandemic on Latinx students and have found ways to adapt to the shift to online learning.
\end{abstract}

Keywords: Latinx, STEM, peer leading, COVID-19, virtual learning 


\section{General Chemistry Peer-Led Team Learning (PLTL) Program at the University of Texas El Paso (UTEP) for Fall 2020}

As an undergraduate Latina student studying Biochemistry at a large Latinx-serving university, I found the shift to virtual learning distressing. It was a difficult adjustment as the resources provided by the school, such as tutoring and library access, were no longer available in person. No longer were we able to ask questions to peers during lectures, gather at the library to study, or go to professors' offices to get help. Instead, we were placed in front of the computer for many hours at a time, feeling very disconnected.

I personally found myself stressed with balancing my course load, especially since I had just started a job as an Emergency Medical Technician. When I was not at work, I sat in front of a computer frustrated, feeling like I was always running out of time. Participating in the Peer Leading program in the chemistry department, however, became an outlet for me and brought me a sense of ease. Having experienced the problems that came with the shift to virtual learning, I was excited as I saw Peer Leading as an opportunity to help others address these issues. It was very empowering to be in a position where I could lead my peers and play a small role in shaping the next generation of Science, Technology, Engineering, and Mathematics (STEM) scholars. It was also a learning experience as I was made aware of the multitude of challenges faced by Latinx students that have not been part of my own personal history.

The Peer-Led Team Learning (PLTL) program for General Chemistry at the University of Texas at El Paso (UTEP) trains undergraduate students (Peer Leaders) to conduct weekly workshops and one-on-one tutoring sessions for students in their first two semesters of Chemistry. All students taking General Chemistry are required to participate in these peer-led workshops in an effort help students excel in their introductory courses. In these workshops, 
there is an emphasis on guiding students toward a better understanding of Chemistry rather than giving them direct answers. Because of this approach, the PLTL program has increased the percentage of students who are passing their Chemistry courses. Additionally, $75 \%$ of Peer Leaders have been Latinx, and about 50\% have been female. Therefore, Latinx Peer Leaders are empowering their own Latinx community by helping them build a strong chemistry foundation for success in their future STEM careers. This is crucial as Latinx individuals, especially Latinas, are largely underrepresented in STEM.

While the PLTL workshops, office hours, and meetings used to take place in person, the pandemic resulted in these activities taking place virtually. This was a large change for former Peer Leaders as many of their workshop activities were designed for in-person learning. Before, students would engage in group work and help each other understand the material. Popular games, such as Jenga and Bingo, were adapted to chemistry games to promote competition and engagement. Students often looked forward to the workshop as it was not only fun but also helpful in strengthening their understanding of chemistry. With the onset of the pandemic, students became discouraged and were hesitant to participate. We had to creatively think of alternative activities and approaches to learning.

Bi-weekly Peer Leader meetings with accessibility to the professors became crucial to the adaptability of the program. We often had discussions about how the pandemic was affecting students in terms of motivation. We started asking: How can we better engage our students? How do we accommodate these rapid and unprecedented changes? How can we create a learning environment that is comfortable and encouraging?

The beauty of our consistent conversations was that from one week to another, we were able to implement these ideas and see their effects. We were analytical about what might have 
encouraged students and what might not have worked. Breakout groups (separating the workshop into smaller groups), for example, has been a learning process. While some groups have thrived and built relationships similar to those that would have been developed in person, other groups are quiet and dread working together. It was up to the Peer Leaders to analyze the response and adjust where necessary. I found that providing a variety of challenges to all groups, creating groups with a mixture of participative and quiet students, and adjusting the size of groups (the smaller the better) were some of the ways in which allowed breakout groups to be an effective tool in workshop.

Since the beginning of the pandemic, Peer Leaders have also created and tested many review games to encourage participation. We have adapted popular board games and game shows which have made learning fun for students. With games, students are often separated into teams and encouraged to solve the practice problems together. After answering, students might be asked to explain the process that led them to the correct answer or try to understand why they might have gotten the question wrong. We have found that students are more likely to participate with games as there is the incentive of "winning." All students win, ultimately, as they have practiced chemistry and have built a stronger understanding. With these techniques, and many more, we have seen a shift in our students. I observed that students who were once unwilling to participate are now engaged in the activities we plan for them. Peer Leading, however, continues to be a learning process as there are always ways in which we may improve and learn.

Filled with and inspired by ideas mentioned in the bi-weekly meetings, I was excited to conduct my own workshop. As I was aware that students felt less connected with their professors and found that learning the material was more difficult in a remote environment, I did all I could to build a relationship with my students and to facilitate their learning. To help close the gap, I 
created a GroupMe (a free group messaging app) so that students could easily communicate their concerns or questions with their peers and Peer Leader. I also began a workshop with a couple of review questions which would help me and the students gauge their understanding of the material and what might need to be reviewed. The practice problems were followed by activities such as Power Point-based games (Connect-Four, Wheel of Fortune, etc.) which never failed to make the students excited and attentive. Reiterating the resources available, such as office hours and review sessions with Spanish-speaking Peer Leaders, was also important to me as it reminded students that they were not alone.

While conducting my first semester of Peer Leading, however, I found that I learned much more from my students than they could have ever learned from me. Given that I live in a largely Latinx community, I experienced the ways in which the pandemic affected Latinx students. While some students were in their first semester of college and struggling to transition effectively from high school, others were parents struggling to balance going to class while having to attend to their children. Some students were economically disadvantaged and could not afford a computer or stable internet. Other students were from Ciudad Juarez, Mexico, our bordering city, and had an added language barrier when learning concepts. At the same time, there were many students or family members of students, that contracted the coronavirus which in turn, affected their performance. Surprisingly, it was these very students, the ones who were the most affected by the pandemic, who were the most motivated to learn. Despite having many reasons to put their academic courses to the side, these students were the ones who asked the most questions, went to office hours, and performed better on exams.

Peer Leading was indeed a transformational experience as learning about the struggles of other individuals during the pandemic and their resilience motivated me to be a better Peer 
Leader and a better student in my own courses. To help my students, I became conscientious and accommodating; something that students need from their instructors to be academically successful during this time. To do so, I tried to make concepts and activities as understandable and effective as possible by responding to different types of learners (auditory, visual, etc.) as well as using my proficiency in Spanish to help diminish any language barrier. Other Peer Leaders have done the same in their own workshops and have even conducted review sessions in both English and Spanish and have created videos explaining concepts better to help our students.

I hope this experience may never be forgotten by Peer Leaders as this semester has taught us much more than chemistry. We have learned about the adaptability and resilience of our Peer Leaders and Latinx students. Despite struggling with economic problems, language barriers, or any other circumstance that resulted from belonging to a marginalized group in the pandemic, many of these students are extremely motivated to succeed. We have learned that a pandemic can place a large obstacle in front of us, but it cannot take away our dreams and our desire to pursue them. We, as Latinx students, are strong and adaptable. Now more than ever, I find that it is my duty as a Latina Peer-Leader to be accommodating and creative when it comes to my workshops so that I may uplift my underrepresented peers and play a part in their success. 